\title{
Primary follicular non-Hodgkin's lymphoma of the ureter: A case report and literature review
}

\author{
ZHIHONG DAI, ZHIYU LIU, YUREN GAO and LIANG WANG
}

Second Department of Urology, Second Affiliated Hospital of Dalian Medical University, Dalian, Liaoning 116011, P.R. China

Received October 29, 2014; Accepted March 8, 2016

DOI: $10.3892 / 01.2016 .4524$

\begin{abstract}
Ureteral cancer is a rare type of neoplasm, with the most prevalent forms including squamous cell carcinoma, transitional cell carcinoma and adenocarcinoma. Ureteral lymphoma is particularly uncommon, and forming a pre-operative diagnosis of the disease is often difficult. The current study describes the case of a 31-year-old man presenting with a space-occupying lesion located in the left lower ureter. Follicular non-Hodgkin's lymphoma was diagnosed via intraoperative frozen section and post-operative pathological analysis. The affected ureteric segment was excised, and the ureter was repaired by end-to-end anastomosis with insertion of a double-J tube for internal drainage. The patient was followed up for 10 months and presented with no signs of recurrence. The current study affirms the importance of pathological examination in the differential diagnosis of ureteral neoplasms and the selection of an appropriate treatment.
\end{abstract}

\section{Introduction}

Ureteral cancer is rare malignant neoplasm of the ureter, and is believed to be associated with environmental stimuli, including tobacco use and exposure to benzidine and $\beta$-naphthylamine. The most prevalent forms of ureteral cancer include transitional cell carcinoma $(>80 \%)$, squamous cell carcinoma $(<10 \%)$ and adenocarcinoma $(<1 \%)$, all of which are highly malignant and are associated with a poor prognosis (1). Ureteral lymphoma is extremely rare, most likely due to the absence of lymphoid tissue in the ureteral wall (2). There are limited descriptions of non-Hodgkin's lymphoma of the ureter in the current literature, with data primarily reported as single cases or small series.

The current study reports the case of a 31-year-old man presenting with follicular non-Hodgkin's lymphoma, which was subsequently treated with surgery; additionally, the diagnosis and treatment of malignant lymphoma of the ureter is

Correspondence to: Dr Zhiyu Liu, Second Department of Urology, Second Affiliated Hospital of Dalian Medical University, 467 Zhongshan Road, Dalian, Liaoning 116011, P.R. China E-mail: 1zydoct@163.com

Key words: follicular lymphoma, ureter, non-Hodgkin's lymphoma discussed with reference to the present case and the relevant literature.

\section{Case report}

In September 2013, a 31-year-old man was referred to the Second Affiliated Hospital of Dalian Medical University (Dalian, China) in 2013 presenting with pain and discomfort in the lower left back. A urinary ultrasound revealed left kidney hydronephrosis and left ureteral expansion. The patient did not present with any marked clinical symptoms, including gross hematuria, frequent micturition or urinary urgency. The blood routine and biochemical parameters were within the normal ranges, with the exception of an elevated serum creatinine level of $143 \mathrm{mmol} / \mathrm{l}$ (normal range, 90-120 mmol/l). Voiding urethrocystography was performed three times, however, the results were negative. A computed tomography (CT) urogram revealed a progressive, space-occupying lesion (measuring $20 \times 16 \mathrm{~mm}$ ) located in the lower left ureter; this was preliminarily considered to be a ureteral tumor (Fig. 1). Emission CT of the kidney indicated that renal function was impaired, as evidenced by a marked decrease in the glomerular filtration rate of the left kidney ( $29.7 \mathrm{ml} / \mathrm{min}$; normal range, 40-60.0 $\mathrm{ml} / \mathrm{min}$ ) and a compensatory increase in the glomerular filtration rate of the right kidney $(73.8 \mathrm{ml} / \mathrm{min}$; normal range, 40-60.0 $\mathrm{ml} / \mathrm{min}$ ).

A flexible ureteroscopy was performed on the patient for further examination, with the scope inserted $6 \mathrm{~cm}$ into the left stoma; this identified luminal stenosis of the left ureter presenting with a stiff ureteral wall. Pathological specimens were not successfully acquired during this procedure, therefore, exploratory surgery was performed to form a definitive diagnosis. During surgery, the lesion (measuring $\sim 3 \times 1 \mathrm{~cm}$ ) was observed to be located in the ureter, $\sim 4 \mathrm{~cm}$ from the bladder. The affected ureteric segment presented with stiff walls and was severely distended, whilst the ureteral mucosa was smooth with integrity. The ureteric segment was excised $1 \mathrm{~cm}$ from the tumor. The lesion was a spindle-shaped neoplasm, and appeared gray-white in color under the blood pictured in Fig. 2.

Analysis of the intraoperative frozen sections demonstrated lymphoid tissue hyperplasia in the left lower ureter. The ureters were repaired by end-to-end anastomosis with insertion of a double-J tube for internal drainage. Post-operative pathological examination utilizing hematoxylin and eosin and immunohistochemical staining suggested a diagnosis of non-Hodgkin's follicular lymphoma (stage I-II; Fig. 3) (3), and the two cut edges 
Table I. Summary of reported cases of malignant lymphoma of the ureter.

\begin{tabular}{|c|c|c|c|c|c|c|c|}
\hline Author, year & Age, years & Gender & Side & Pathology & Treatment & $\begin{array}{l}\text { Outcome, } \\
\text { follow-up time }\end{array}$ & Refs. \\
\hline $\begin{array}{l}\text { Schniederjan and } \\
\text { Osunkoya, } 2009\end{array}$ & 28 & $\mathrm{M}$ & $\mathrm{R}$ & NHL (DLBCL) & Unknown & SWD, 2.5 years & (5) \\
\hline $\mathrm{Ni}, 2014$ & 61 & M & $\mathrm{L}$ & NHL (DLBCL) & R-CHOP & NED, 6 months & (4) \\
\hline Yoshii, 2010 & 41 & $\mathrm{~F}$ & $\mathrm{R}$ & NHL (DLBCL) & Chemotherapy & SWD, 16 months & (6) \\
\hline \multirow[t]{2}{*}{ Kubota, 2007} & 58 & M & $\mathrm{L}$ & NHL (DLBCL) & PU + chemotherapy & NED, 2 years & (7) \\
\hline & 74 & M & Unknown & NHL (DLBCL) & Unknown & Unknown & (7) \\
\hline $\begin{array}{l}\text { Bhattachary and } \\
\text { Gammall, } 1995\end{array}$ & 26 & M & Bil & NHL (DLBCL) & PU + chemotherapy & Unknown & (8) \\
\hline \multirow[t]{3}{*}{ Kerner, 2008} & 59 & M & $\mathrm{R}$ & NHL (DLBCL) & Unknown & Unknown & (9) \\
\hline & 42 & M & $\mathrm{L}$ & NHL (DLBCL) & R-CHOP & SWD, 2.5 years & (9) \\
\hline & 35 & M & $\mathrm{L}$ & NHL (MALT) & $\mathrm{NU}+\mathrm{R}-\mathrm{CHOP}$ & NED, 1 year & (9) \\
\hline Numakura, 2011 & 72 & M & $\mathrm{R}$ & NHL (MALT) & PU & S, 5 months & (10) \\
\hline Haitani, 2012 & 71 & M & $\mathrm{R}$ & NHL (follicular) & PU & SND, 3.5 years & (2) \\
\hline Kubota, 2007 & 68 & M & Bil & NHL & $\mathrm{NU}+$ chemotherapy & $\mathrm{S}, 3$ years & (7) \\
\hline Salem, 2014 & 69 & $\mathrm{~F}$ & $\mathrm{~L}$ & NHL & PU & SWD, 1 year & (11) \\
\hline Jaegar, 2014 & 22 & $\mathrm{~F}$ & $\mathrm{~L}$ & NHL & $\mathrm{PU}$ & NED,6 months & (12) \\
\hline \multirow[t]{6}{*}{ Kubota, 2007} & 60 & M & $\mathrm{R}$ & NHL & Unknown & Unknown & (7) \\
\hline & 38 & M & $\mathrm{L}$ & NHL & $\mathrm{NU}+$ chemotherapy & NED, 21 months & (7) \\
\hline & 52 & $\mathrm{~F}$ & $\mathrm{~L}$ & $\mathrm{HL}$ & $\mathrm{NU}+$ radiation & Unknown & (7) \\
\hline & 12 & M & $\mathrm{L}$ & $\mathrm{HL}$ & $\mathrm{NU}+$ chemotherapy & NED, 18 months & (7) \\
\hline & 52 & M & $\mathrm{L}$ & $\mathrm{HL}$ & PU & Unknown & (7) \\
\hline & 54 & M & $\mathrm{R}$ & HL & $\mathrm{NU}+$ chemotherapy & NED, 11 months & (7) \\
\hline
\end{tabular}

F, female; M, male; R, right; L, left; Bil, bilateral; NHL, non-Hodgkin's lymphoma; DLBCL, diffuse large B-cell lymphoma; MALT, mucosa-associated lymphoid tissue; NU, nephroureterectomy; PU, partial ureterectomy; S, succumbed with unknown disease status; SND, succumbed with no presence of disease; SWD, succumbed to disease; NED, no evidence of disease; R-CHOP, rituximab, cyclophosphamide, doxorubicin, vincristine and prednisolone.
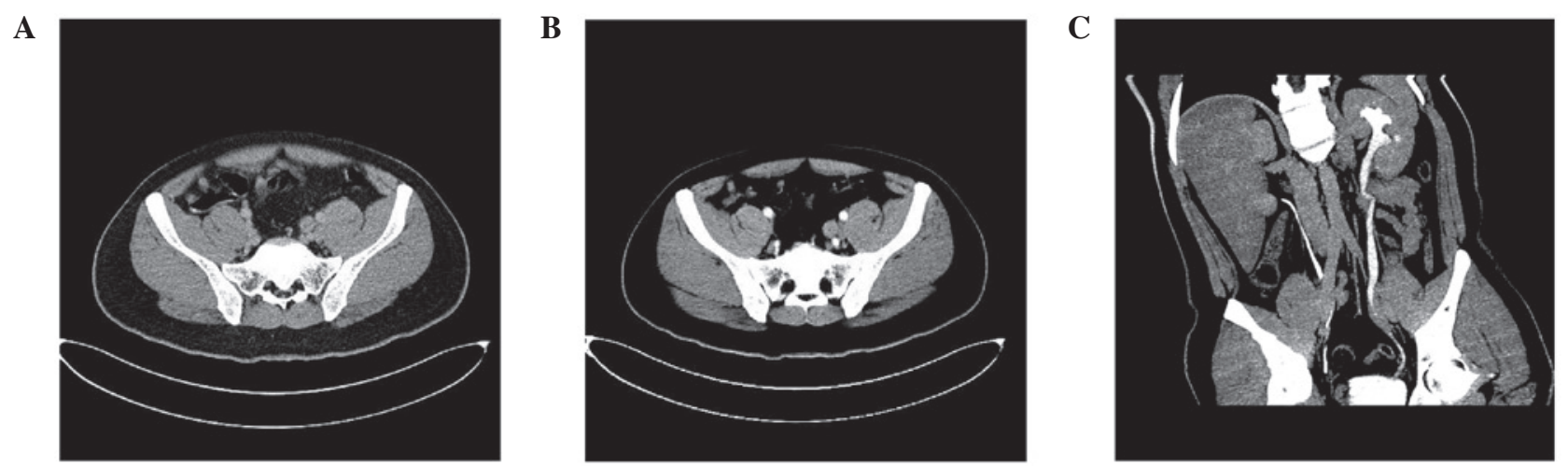

Figure 1. (A) CT scan demonstrating a space-occupying lesion in the lower left ureter. CT value, 22-24 HU. (B) Contrast-enhanced CT scan of the ureter. CT value, 72-82 HU. (C) CT urogram of the ureter (lesion size, 20x16 mm). CT, computed tomography.

of the ureter were free of tumor tissue. The patient was subsequently discharged with satisfactory clinical outcomes without any adjuvant therapy subsequent to surgery; follow-up was conducted for 10 months and no signs of recurrence were noted.

\section{Discussion}

Lymphoma may occur in a single lymph node or within a group. Extranodal lymphoma is used to describe the development of lymphoma in organs or tissues outside the lymphatic system. Primary extranodal lymphomas account for $25-40 \%$ of all non-Hodgkin's lymphoma cases (4). In total, $<5 \%$ of lymphomas occur in the urinary system, with the majority located in the kidneys and bladder (5). Primary lymphoma of the ureter is extremely rare, with only 20 cases previously reported, including 4 cases of Hodgkin's lymphoma and 16 cases of non-Hodgkin's lymphoma (Table I) (4-12). Regarding non-Hodgkin's lymphoma, diffuse large B-cell 


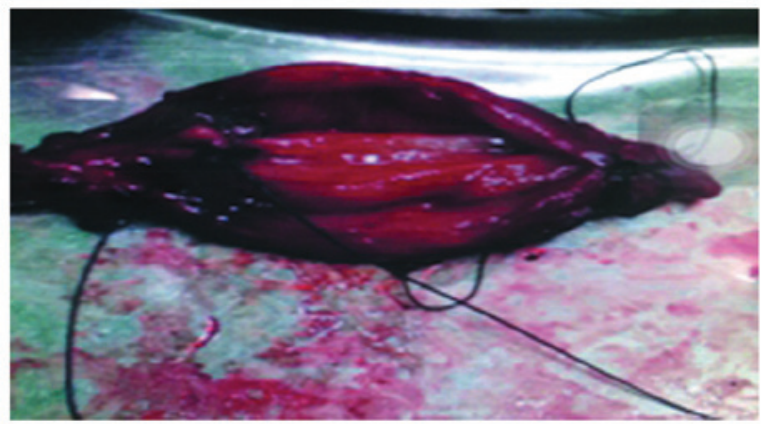

Figure 2. Lymphoma resected during the surgery. The lymphoma was a spindle-shaped neoplasm, gray-white in color (measuring $3 \times 1 \mathrm{~cm}$ ). The affected ureteral mucosa was smooth with integrity.

A

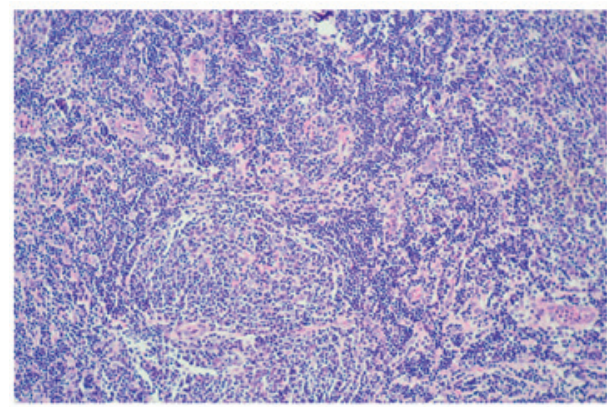

B

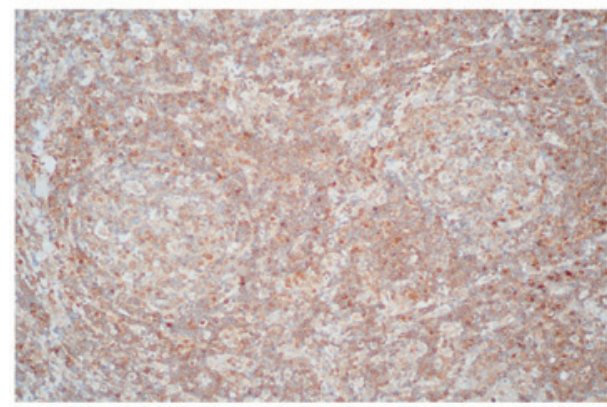

C

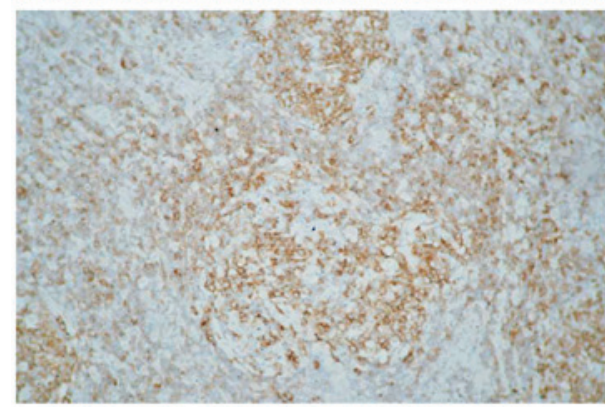

D

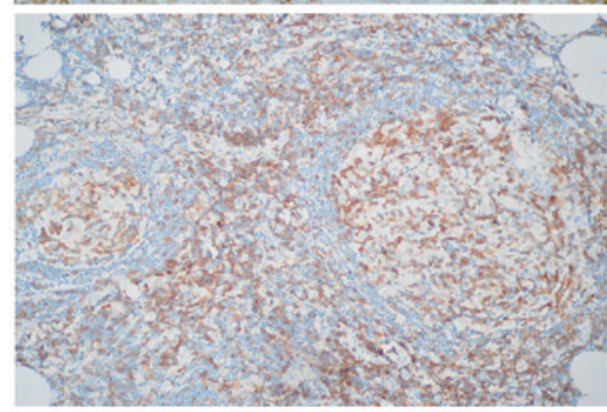

Figure 3. Post-operative pathological examination. (A) Hematoxylin-eosin staining exhibited atypical lymphocytes from follicular nodules. Immunohistochemical staining demonstrated positive expression for (B) Bcl-2, (C) CD20 and (D) CD3 in the nodular soft-tissue mass located in the left ureter. Magnification, x200. Bcl-2, B-cell lymphoma 2; CD, cluster of differentiation lymphoma is the most prevalent histological type, whilst follicular lymphoma is particularly rare. Ureteral lymphoma is more frequent in men than in women. The majority of reported cases of ureteral lymphoma were unilateral, with only two cases discussing the occurrence of bilateral ureters $(7,8)$.

Painless gross or microscopic hematuria is commonly observed in patients presenting with ureteral carcinoma (13). However, individuals with follicular lymphoma often have limited clinical symptoms. In the current study, the patient exhibited soreness and pain in the left waist area and hydronephrosis as a result of ureterostenosis, with little or no hematuria.

Currently, there are no specific diagnostic methods available to detect ureteral lymphoma, and forming a pre-operative diagnosis is challenging. Routine surveillance imaging has a limited role in diagnosis. Ultrasonography is only capable of indicating possible ureteral expansion above the lesion and ipsilateral hydronephrosis, whilst intravenous urography only detects ureterostenosis in the lesion segment. CT may identify a space-occupying lesion with ureteral wall thickening and ureterostenosis, however, it cannot identify the nature of the lesion. Therefore, it is difficult for CT to differentiate ureteral lymphoma from other ureteral tumors, such as transitional cell and squamous cell carcinoma.

It is believed that combining multiple imaging modalities, including positron emission tomography/CT and CT urography, may improve the diagnostic rate of ureteral lymphoma (14). Since there are no definitive imaging characteristics associated with the disease, ureteroscopic biopsy or surgical exploration appear to be necessary to form a definite diagnosis (15). It is reported that laparoscopic ureteral needle biopsy, a minimally invasive technique, typically leads to a pathological diagnosis (16). In the present case, when the ureteroscopy failed to successfully collect pathological specimens, the patient underwent exploratory surgery. Thereafter, the diagnosis was established based on intraoperative frozen sections and post-operative pathological examination.

There are two types of lymphocytes: B and T lymphocytes. The majority of non-Hodgkin's lymphomas, including follicular lymphoma, are B-cell type. The etiology of follicular non-Hodgkin's lymphoma is currently unknown, but it is believed to be associated with viral infection (such as infection with the Epstein-Barr virus or human herpes virus-8) or specific gene alterations (including those in B-cell lymphoma 2) $(17,18)$.

Follicular lymphoma is a form of low-grade lymphoma, implying that the tumors are typically slow-growing and that it may take a number of years for the disease to progress. Thus, treatment is not always required upon diagnosis, but is dependent on the individual requirements of the patient. A study by Brice et al (19) compared the three following therapeutic options regarding follicular lymphoma: i) Delay of any treatment until clinically significant progression is observed; ii) immediate treatment with an oral alkylating agent; or iii) treatment with interferon- $\alpha$ for patients with follicular lymphoma and a low tumor burden. Notably, it was determined that delayed treatment is feasible and does not hamper the prognosis or subsequent response to treatment (19). However, a lymphoma of the ureter typically leads to ureteral obstruction, which may cause progressive deterioration of kidney function if left untreated, as in the 
present study. Therefore, lymphomas and affected ureteric segments require resection as early as possible.

Even in the advanced stages of the disease, a patient with follicular lymphoma often survives for a long period of time (2). However, the disease is difficult to cure completely, and active treatment is required when a patient presents with clinical symptoms. Such treatments may include various combinations of chemotherapy, radioimmunotherapy, monoclonal antibodies or autologous or allogeneic hematopoietic stem cell transplantation. In recent years, rituximab (anti-cluster of differentiation 20 monoclonal antibody) has become the primary first-line therapy for follicular lymphoma patients, with a high rate of complete clinical and molecular remission $(20,21)$. However, in the present case, the patient did not require any auxiliary treatment following surgery, possibly due to early diagnosis and treatment. The patient was followed up for 10 months without any signs of recurrence.

In conclusion, the current study affirms the importance of pathological examination in the differential diagnosis of ureteral neoplasms. Lymphoma of the ureter, in cases of ureteral obstruction, typically requires prompt and appropriate treatment to prevent progressive impairment of renal function.

\section{References}

1. Rouprêt M, Babjuk M, Compérat E, Zigeuner R, Sylvester RJ, Burger M, Cowan NC, Böhle A, Van Rhijn BW, Kaasinen E, et al: European Association of Urology Guidelines on Upper Urinary Tract Urothelial Cell Carcinoma: 2015 Update. Eur Urol 68: $868-879,2015$.

2. Haitani T, Shimizu Y, Inoue T, Okubo K, Watanabe J, Kamba T, Yoshimura K, Kanematsu A, Nishiyama $\mathrm{H}$, Ogawa O, et al: A case of ureteral malignant lymphoma with concentric thickening of the ureteral wall. Hinyokika Kiyo 58: 209-213, 2012 (In Japanese).

3. Fauzi MF,Pennell M,Sahiner B, Chen W, Shana'ah A,Hemminger J, Gru A, Kurt H, Losos M, Joehlin-Price A, et al: Classification of follicular lymphoma: The effect of computer aid on pathologists grading. BMC Med Inform Decis Mak 15: 115, 2015.

4. Ni BW, Zhong L, Wang T and Chen FY: Malignant lymphoma of the ureter: A case report and literature review. Exp Ther Med 7: 1521-1524, 2014.

5. Schniederjan SD and Osunkoya AO: Lymphoid neoplasms of the urinary tract and male genital organs: A clinicopathological study of 40 cases. Mod Pathol 22: 1057-1065, 2009.

6. Yoshii T, Horiguchi A, Shirotake S, Tobe M, Hayakawa M, Sumitomo M and Asano T: Spontaneous rupture of the ureter as the primary symptom of malignant lymphoma. Hinyokika Kiyo 56: 639-643, 2010 (In Japanese)

7. Kubota Y, Kawai A, Tsuchiya T, Kozima K, Yokoi S and Deguchi T: Bilateral primary malignant lymphoma of the ureter. Int J Clin Oncol 12: 482-484, 2007.
8. Bhattachary V and Gammall MM: Bilateral non-Hodgkin's intrinsic lymphoma of ureters. Br J Urol 75: 673-674, 1995.

9. Kerner A, Ott HW and Potthast S: Ureteral metastases - rarely radiologically diagnosed: Case series of carcinoid and non-Hodgkin lymphoma. Rofo 180: 153-155, 2008 (In German).

10. Numakura K, Tsuchiya N, Obara T, Tsuruta H, Saito M, Narita S, Inoue T, Horikawa Y, Satoh S and Habuchi T: A case of ureteral malignant lymphoma diagnosed by laparoscopic needle biopsy. Jpn J Clin Oncol 41: 440-442, 2011.

11. Salem AB, Nfoussi $H$ and Kchir N: Ureteral spread of a primary cutaneous diffuse large B-cell lymphoma, leg type. Indian J Urol 30: 222-224, 2014.

12. Jaeger CD, McAlvany KL, Zingula SN, Kramer SA and Granberg CF: Diffuse large B-cell lymphoma in an adolescent male presenting as ureteral stricture. Case Rep Radiol 2014: 239345, 2014

13. Rouprêt M, Zigeuner R, Palou J, Boehle A, Kaasinen E, Sylvester R, Babjuk M and Oosterlinck W: European guidelines for the diagnosis and management of upper urinary tract urothelial cell carcinomas: 2011 update. Eur Urol 59: 584-594, 2011.

14. Ghersin E, Keidar Z, Eldad DJ, Bar-Shalom R, Fischer D and Halachmi S: Multimodality imaging of direct ureteric involvement in non-Hodgkin's lymphoma using PET/CT, CT urography and antegrade CT pyelography. Br J Radiol 80: e283-e286, 2007.

15. Hashimoto H, Tsugawa M, Nasu Y, Tsushima T and Kumon H: Primary non-Hodgkin lymphoma of the ureter. BJU Int 83: 148-149, 1999.

16. Numakura K, Tsuchiya N, Obara T, Tsuruta H, Saito M, Narita S, Inoue T, Horikawa Y, Satoh S and Habuchi T: A case of ureteral malignant lymphoma diagnosed by laparoscopic needle biopsy. Jpn J Clin Oncol 41: 440-442, 2011.

17. Martini M, Capello D, Serraino D, Navarra A,Pierconti F, Cenci T, Gaidano G and Larocca LM: Characterization of variants in the promoter of EBV gene BZLF1 in normal donors, HIV-positive patients and in AIDS-related lymphomas. J Infect 54: 298-306, 2007.

18. Bosga-Bouwer AG, van Imhoff GW, Boonstra R, van der Veen A, Haralambieva E, van den Berg A, de Jong B, Krause V, Palmer MC, Coupland R, et al: Follicular lymphoma grade 3B includes 3 cytogenetically defined subgroups with primary $\mathrm{t}(14 ; 18), 3 \mathrm{q} 27$, or other translocations: $\mathrm{T}(14 ; 18)$ and $3 \mathrm{q} 27$ are mutually exclusive. Blood 101: 1149-1154, 2003.

19. Brice P, Bastion Y, Lepage E, Brousse N, Haïoun C, Moreau P, Straetmans N, Tilly H, Tabah I and Solal-Céligny P: Comparison in low-tumor-burden follicular lymphomas between an initial no-treatment policy, prednimustine, or interferon alfa: A randomized study from the Groupe d'Etude des Lymphomes Folliculaires. Groupe d'Etude des Lymphomes de l'Adulte. J Clin Oncol 15: 1110-1117, 1997.

20. Czuczman MS, Weaver R, Alkuzweny B, Berlfein J and Grillo-López AJ: Prolonged clinical and molecular remission in patients with low-grade or follicular non-Hodgkin's lymphoma treated with rituximab plus CHOP chemotherapy: 9-year follow-up. J Clin Oncol 22: 4711-4716, 2004.

21. Colombat P, Salles G, Brousse N, Eftekhari P, Soubeyran P, Delwail V, Deconinck E, Haïoun C, Foussard C, Sebban C, et al: Rituximab (anti-CD20 monoclonal antibody) as single first-line therapy for patients with follicular lymphoma with a low tumor burden: Clinical and molecular evaluation. Blood 97: 101-106, 2001. 